\title{
Effect of moisture and sonication time on dielectric strength and heat transfer performance of transformer oil based $\mathrm{Al}_{2} \mathrm{O}_{3}$ nanofluid
}

\author{
S. Ravi Babu ${ }^{1 *}$, N.V.A Ravi Kumar ${ }^{2}$ and P. Ramesh Babu ${ }^{3}$ \\ Department of Mechanical Engineering, GMR Institute of Technology, Rajam, A.P, India ${ }^{1}$ \\ Department of Electrical Engineering, GMR Institute of Technology, Rajam, A.P, India ${ }^{2}$ \\ Department of Mechanical Engineering, SASI Institute of Technology \& Engineering, Tadeplligudem, India ${ }^{3}$
}

Received: 18-June-2021; Revised: 11-September-2021; Accepted: 12-September-2021

(C)2021 S. Ravi Babu et al. This is an open access article distributed under the Creative Commons Attribution (CC BY) License, which permits unrestricted use, distribution, and reproduction in any medium, provided the original work is properly cited.

\begin{abstract}
The dielectric breakdown strength of transformer oil plays an important role in the performance of transformers. The presence of moisture and excess heat in the transformer oil degrade its performance. In this study, the effect of moisture and sonication time on dielectric strength, stability, and heat transfer performance is investigated experimentally. Nanofluids are the colloidal homogenous suspensions, prepared by dispersing the nanoparticles $(<100$ nm) in the required quantity. Nanoparticles consist of good thermo-physical properties like thermal conductivity, specific heat, etc. By dispersing nanoparticles into base fluids, nanofluid shows improved properties compared to base fluids. $\mathrm{Al}_{2} \mathrm{O}_{3}$ nanoparticles based nanofluid is a proven heat transfer fluid for the applications like automobile radiators, electronic cooling, nuclear cooling, etc. So, in the present study, transformer oil - $\mathrm{Al}_{2} \mathrm{O}_{3}$ nanofluid is considered to study the effect of moisture on the heat transfer performance and breakdown strength. Results indicated that the performance of transformer oil nanofluid was decreased with an increase in the moisture content present in it. Also, breakdown voltage and heat transfer coefficient were maximum at $0.1 \%$ volume fraction of nanofluid.
\end{abstract}

Keywords

Dielectric strength, Nanofluid, Moisture, Sonication time, Heat transfer.

\section{Introduction}

Power transformer's role is very much critical in the transmission and distribution of electricity to the consumers from power stations. The insulating liquid is crucial to the performance of the transformer [1]. Transformers expose to various stresses like thermal, electric, and chemical during their operation. Periodical checkups and maintenance of insulating oil in the transformer are very much required to prevent sudden failure [2]. One of the most detrimental elements to transform paper and oil insulation is moisture. It weakens the dielectric and lowers the Partial Discharge (PD) inception voltage, affects the electrical characteristics [3]. Aging and external causes are the two most important variables that encourage moisture intrusion in transformers. The moisture equilibrium characteristics of oil and paper insulation are well-known and broadly applied to estimate how much moisture is involved.

\footnotetext{
*Author for correspondence
}

Oil, on the other hand, can lose its insulating properties if it is polluted by moisture, particles, or a combination of the two [4]. Moisture contamination is thought to happen when voltage load tapes are changed, allowing moisture and gases to absorb. The deterioration of the paper insulation between the transformer windings causes particle pollution [5].

Transformers are built to withstand large loads, such as emergency and cold load pickup circumstances. As the load on the transformer grows, the internal temperature rises, which in turn reduces the transformer's typical life expectancy. This process might take anything from months to years. Characteristics of a good cooling liquid include high thermal conductivity, low vis cosity, high specific heat, high dielectric strength (in case of direct liquid cooling), high surface tension, chemical inertness, chemical stability, low freezing point, and melting points, and low cost. Insulating liquids need to retain their electrical and thermo-physical properties for a long time [6]. But in practice, after using those oils for a long time they lose their properties. In order to 
maintain the properties of insulating liquids for a long time nanoparticles are added by the researchers [7].

\subsection{Background of the work}

The fast progression of modern power systems demands high-performance transformers according to less energy consumption, higher density and faster response [8]. So, improvement of the thermal conductivity, dielectric strength and heat transfer performance of insulating oil is the need of the hour. The superior properties of the nanofluid entice the research community to pursue research with nanofluid in a variety of fields. Figure 1 depicts the researcher's work on nanofluid so far, along with the number of publications year by year. According to the Web of Science search results (Searched with the keywords 'nanofluid' and the corresponding 'year'), it is observed that the publications on nanofluid have increased exponentially and seen significant growth from the last 3 to 4 years as a result of the latest developments in the field of nanofluid. The majority of the study of the literature focuses on the dielectric strength and electrical characteristics of different insulating oils. However, there is a paucity of research on the heat transfer properties of transformer-based Nanofluids and the effects of moisture and sonication duration on dielectric strength. It prompted the researchers to conduct the tests to see how moisture affected the dielectric strength and heat transfer performance of a transfer oil-based $\mathrm{Al}_{2} \mathrm{O}_{3}$ nanofluid at different volume concentrations.

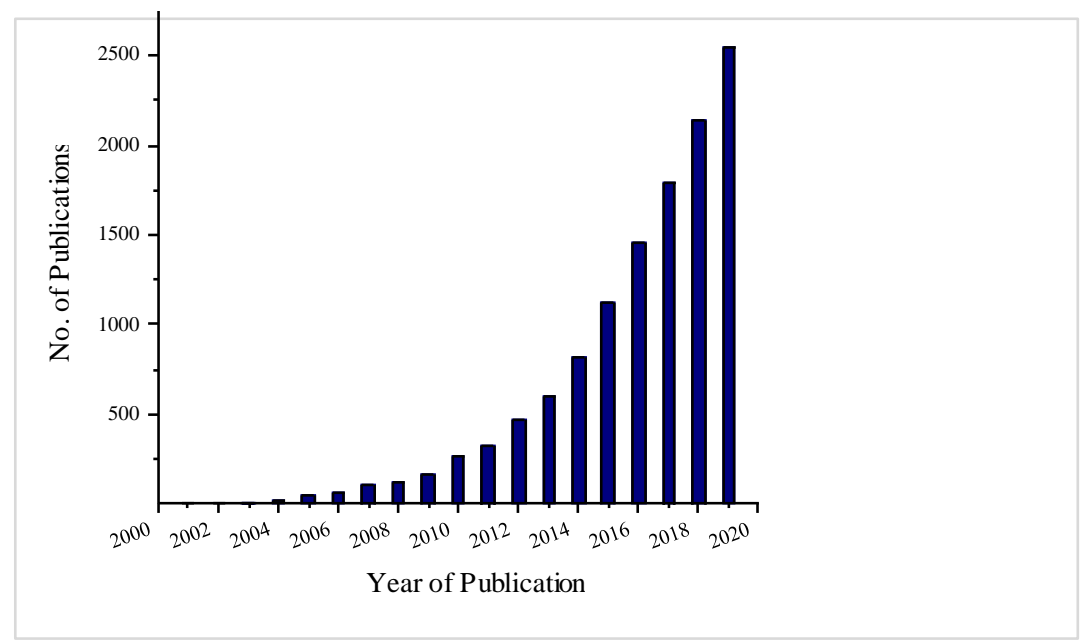

Figure 1 Publications of nanofluids year-wise (Source: Web of Science)

\section{Literature review}

Fernandez et al. [1] have experimentally investigated the effect of titania, Zinc oxide-based natural ester nanofluid (used as transformer oil) to determine the performance based on stability and thermal aging. They observed that the addition of nanoparticles improves dielectric strength and enhances the life s pan of insulation liquids.

Farade et al. [2] have conducted the experiments to know the effect of ultrasonication time on stability, dielectric properties, and temperature of graphenebased natural ester nanofluid and found better stability and high dielectric strength is achieved at $60 \mathrm{~min}$. of sonication.

$\mathrm{Xu}$ et al. [3] have discussed the mechanisms of modification for transformer oil based nanofluid and observed that the reduction of additives gives improved stability to the fluids.

1223
Rafiq et al. [4] have conducted a review of the literature on transformer oil nanofluid to better understand the effect of nanoparticles on thermophysical and electrical properties of insulating liquids and also summarized the outcomes of those studies.

Bhatt and Bhatt [5] have reviewed the various studies done on electrical properties of transformer oil nanofluid and presented the summary of the review.

Suhaimi et al. [6] have reviewed and presented the synthesis of nanofluid, the effect of nanoparticles on the performance of dielectric strength of insulating liquid and limitations of Nanofluids to be avoided to make the nanofluid commercially available.

Lv et al. [7] have prepared titania -transformer oil nanofluid using different dispersion methods to know 
their effect on stability and dielectric strength and observed that the stirring method proves to be the best one among other ones.

Ghani et al. [8] have prepared palm oil-based nanofluid and conducted the experiments to find out the effect of moisture on breakdown strength and other characteristics of insulating oils.

Kiran and Ravi $[9,10]$ have prepared water - $\mathrm{Al}_{2} \mathrm{O}_{3}$ nanofluid at different volume concentrations and conducted experiments with the fabricated experimental setup to find the performance of natural convective heat transfer using water- $\mathrm{Al}_{2} \mathrm{O}_{3}$ nanofluid.

Ashiquzzaman et al. [11] have tested the breakdown strength of transformer oil and insulation paper and also tested the corona effect of various conductors as per ASTM and IEC standards.

Danikas et al. [12] have reviewed the literature based on the experiments conducted to know the effect of the factors like conditioning effect, oil flow, applied voltage, and electronic configuration on the dielectric strength and observed that the velocity and impurities have a considerable effect on breakdown strength.

Ghoneim et al. [13] have measured the dielectric characteristics of the prepared barium titanate and nickel ferrite-based transformer oil nanofluid at various particle loadings such as 25,50 , and $75 \mathrm{mg} / 1$ and observed the enhancement in dielectric strength.

Sumathi et al. [14] have prepared $\mathrm{TiO}_{2} / \mathrm{Al}_{2} \mathrm{O}_{3} / \mathrm{MoS}_{2}$ based transformer oil hybrid nanofluid at particle loadings $0.01,0.025,0.05,0.1 \%$ to test the dielectric strength based on L16 orthogonal array using TAGUCHI technique and analyzed the results based on ANOVA and observed that the percentage weight of $\mathrm{TiO}_{2} / \mathrm{Al}_{2} \mathrm{O}_{3}$ influenced the dielectric strength very much.
Kunju and Shemim [15] have synthesized $\mathrm{TiO}_{2}$, $\mathrm{Fe}_{2} \mathrm{O} 3$, SiO2, h-BN, $\mathrm{Al}_{2} \mathrm{O}_{3}$ based transformer oil nanofluid for measuring breakdown voltage, viscosity for different samples and observed that the nanofluid with white graphene has superior characteristics.

Abdi et al. [16] have conducted experiments to measure and correlate the effect of water content on the electrical properties of mineral oil and observed that after treatment, the breakdown voltage is increased as water content decreases.

Safiddin et al. [17] have taken the used transformer oil and with the help of the membrane separation technology, process its life is enhanced by eliminating carboxylic acids.

Ali and Salam [18] have reviewed the preparation, characterization, stability and heat transfer mechanisms of nanofluid and summarized them.

Ji et al. [19] have done the study on preparation and the heat transfer augmentation of nanofluid presented.

Zhou et al. [20] have conducted experiments to measure the modified the behaviour of creeping streamers at $\mathrm{TiO}_{2}$ nanofluid and the interface of Pressboard and observed the enhanced performance. Summary of the literature review is presented in Table 1. Form the literature review, it is observed that several researchers have done the experiments to determine dielectric strength and determined the temperature and viscosities of the prepared nanofluid. Several reviews are done by researchers and summarized all the findings and presented the various challenges associated with the preparation, characterization and measurement of breakdown strength. Few of the experiments are conducted to determine the heat transfer performance of nanofluid.

Table 1 Summary of literature review

\begin{tabular}{llll}
\hline S. No & Author reference & Nanoparticle material & Remarks \\
\hline 1 & {$[1,15,20]$} & $\mathrm{Al}_{2} \mathrm{O}_{3}$ & Dielectric strength, viscosity \\
\hline 2 & {$[2]$} & $\mathrm{Graphene}_{\text {strength, }}$ & $\begin{array}{l}\text { Dielectric } \\
\text { temperature }\end{array}$ \\
\hline 3 & & Heat transfer studies \\
\hline 4 & {$[9,10]$} & $\mathrm{Al}_{2} \mathrm{O}_{3}$ & Dielectric strength \\
\hline 5 & {$[14,15]$} & $\mathrm{Al}_{2} \mathrm{O}_{3}$ & Dielectric strength \\
\hline 6 & {$[15]$} & $\mathrm{SiO}_{2}$ & Dielectric strength, ANOVA \\
\hline 7 & {$[14,15]$} & $\mathrm{MoS}_{2}$ & Dielectric strength \\
\hline 8 & {$[15]$} & $\mathrm{Fe}_{2} \mathrm{O}_{3}$ & Dielectric strength \\
\hline 9 & {$[15]$} & $\mathrm{BN}$ & Reviews \\
\hline
\end{tabular}


2.1Motivation and objectives of present study The majority of the research in the literature is focused on the dielectric strength of various insulating oils and their electrical properties. But there is not much literature available on the heat transfer performance of transformer based nanofluid and the effect of moisture and sonication time on dielectric strength. These points have motivated the authors to conduct the experiments to determine the effect of moisture on dielectric strength and heat transfer performance of transfer oil based $\mathrm{Al}_{2} \mathrm{O}_{3}$ nanofluid at various volume concentrations.

\section{Methodology}

Transformer oil- $\mathrm{Al}_{2} \mathrm{O}_{3}$ nanofluid was prepared by a two-step method in which Alumina nanoparticles are dispersed in the required proportion according to the volume concentration of the nanofluid based on (1). Alumina nanoparticles of $30-50 \mathrm{~nm}$ particle size with $99.5 \%$ purity were purchased from Nano Labs, India.

\subsection{Preparation of Nanofluids}

The first phase of the two-step method shown in Figure 2, involves the preparation of nanoparticles, followed by dispersion of nanoparticles in the base fluid, stirring, and ultrasonication. To keep the nanoparticles from settling, oleic acid with 1/10th amount of nanoparticles is used as the surfactant. Excess surfactant use is not recommended because as it may impede the thermo-physical properties [9].

After determining the mass of nanoparticles for preparing nanofluid with the help of digital balance (Shimadzu), these particles and surfactant were dispersed in the transformer oil and stirred with a magnetic stirrer for half an hour, and mixture was then sonicated with an ultrasonic sonicator (Oscar Electronics) at $20 \mathrm{kHz}$ frequency and different sonication times of 1 hour, 2 hour and 3 hours and with a 5 minutes break for every 15 minutes of operation to avoid the increase in temperature of the nanofluid [10]. Block diagram of the entire methodology of the current work is presented in Figure 3.

Vol. fraction of nanofluid is shown in Equation 1.

$$
=\frac{\left(m_{n p} / \rho_{n p}\right)}{\left({ }^{m_{n p}} / \rho_{n p}\right)+\left({ }^{m_{b f}} / \rho_{b f}\right)}
$$

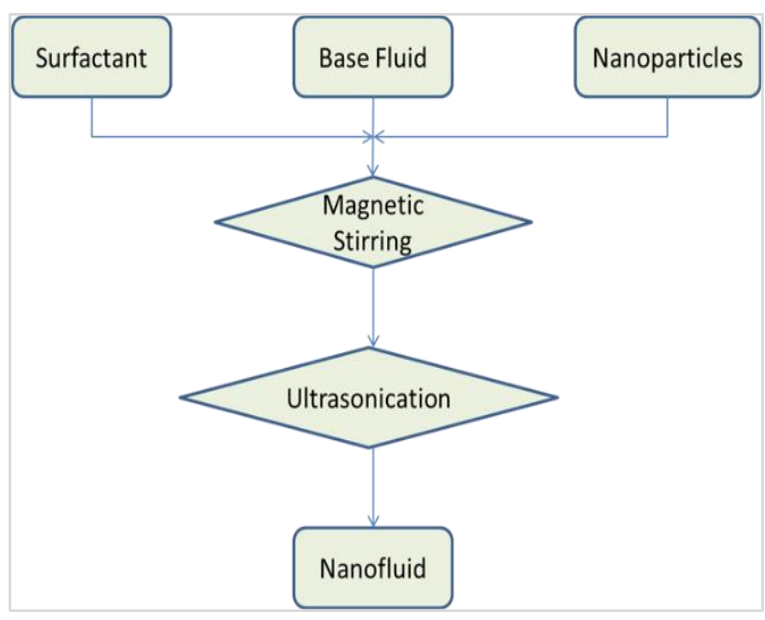

Figure 2 Flow diagram of nanofluid preparation using a two-step method

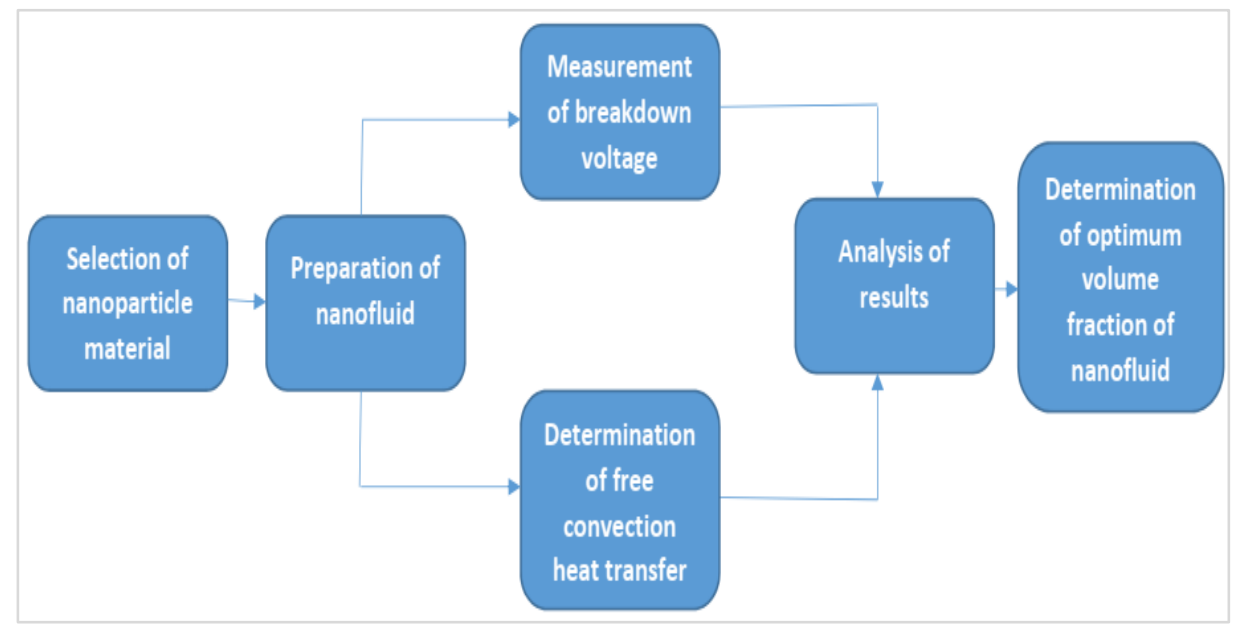

Figure 3 Block diagram of the methodology of the work 


\section{Experimental setup}

After preparing the transformer oil $-\mathrm{Al}_{2} \mathrm{O}_{3}$ nanofluid, breakdown voltage, and heat transfer performance was determined.

\subsection{Measurement of breakdown voltage}

Prepared transformer oil - $\mathrm{Al}_{2} \mathrm{O}_{3}$ nanofluid was taken into the oil tester (High Voltage, India) to measure the AC breakdown voltage as per IEC 156 standards. As per this standard, a $2.5 \mathrm{~mm}$ gap between two test electrodes and a $2 \mathrm{kV} / \mathrm{s}$ ramp rate in the voltage was maintained.

The picture of the top view of an oil tester is shown in Figure 4. Measurement was done at roomtemperature and the test was repeated five times with a 5-minute break between each test and the average value was considered as breakdown voltage [9].

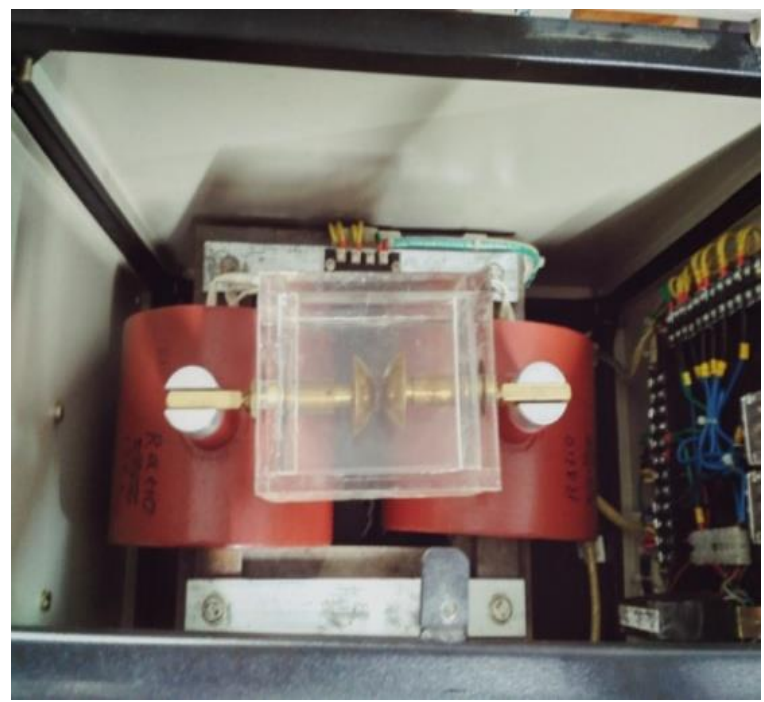

Figure 4 Breakdown strength measuring oil tester

\subsection{Determination of heat transfer performance}

The experimental setup, shown in Figure 5, was fabricated for conducting the experiments in order to determine the performance of free convective heat transfer for various heat fluxes and at various concentrations of transformer oil based alumina nanofluid [10]. It consists of an aluminium test enclosure where nanofluid was filled, outside shell with the cooling water flow arrangement, vertical cylinder with heater, data acquisition system and Teflon coated Cr-Al type thermocouples. Reynold's number should be greater than 1708 for the occurrence of natural convection and with the current experimental set up even at $10 \mathrm{~W}$ of heat input also buoyancy-induced flow exists. Thermocouples (6 No's) were brazed on the vertical cylinder to measure the temperatures at the corresponding points on the cylinder.

Six thermocouples were kept in the liquid at the same level of thermocouples mounted on the cylinder to measure the temperature difference between the cylinder and the nanofluid at the same height. While conducting the experiments, all the fans in the room were switched off to get proper natural convection inside the enclosure. At a particular heat input, by regulating the cooling water circulation, the temperature of the walls of the enclosure was kept constant. For heat inputs ranging from $30 \mathrm{~W}$ to $50 \mathrm{~W}$, the flow rate of the cooling water circulation was kept in the range of 1.43 l.p.m to 2.23 l.p.m to sense the heat from the cooling water completely so that the wall of the enclosure was kept constant. For every experimental analysis, uncertain analysis is to be conceded. In general, mathematical expression of measuring uncertainty is shown in Equation 2 to Equation 5.

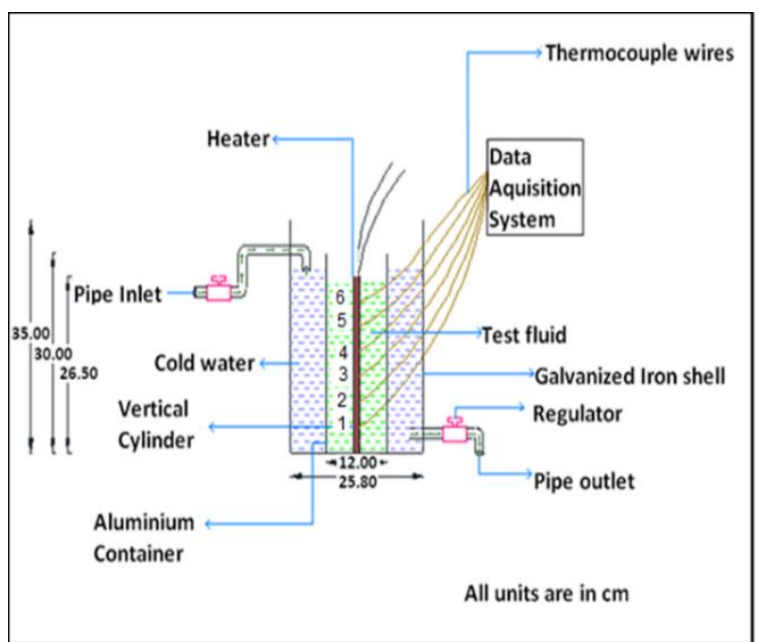

Figure 5 Experimental set up of natural convection heat transfer

$[\varepsilon(F)]^{2}=\left[\frac{\partial F}{\partial x_{1}} \varepsilon\left(x_{1}\right)\right]^{2}+\left[\frac{\partial F}{\partial x_{2}} \varepsilon\left(x_{2}\right)\right]^{2}+. .+\left[\frac{\partial F}{\partial x_{i}} \varepsilon\left(x_{i}\right)\right]^{2}$

Where $F$ is the quantity to be calculated, $\varepsilon$ is uncertainty, $\mathrm{x}_{1}, \mathrm{x}_{2}, \mathrm{x}_{3}$ are variables.

If it is applied to convection heat transfer, heat transfer coefficient $h=\frac{Q}{A(\Delta T)}$

$$
[\varepsilon(h)]=\sqrt{\left[\frac{\partial h}{\partial Q} \varepsilon(Q)\right]^{2}+\left[\frac{\partial h}{\partial A} \varepsilon(A)\right]^{2}+\left[\frac{\partial h}{\partial \Delta \mathrm{T}} \varepsilon(\Delta \mathrm{T})\right]^{2}}
$$


$[\varepsilon(h)]=\sqrt{\left[\frac{1}{A \Delta \mathrm{T}} \varepsilon(Q)\right]^{2}+\left[\frac{-Q}{A^{2} \Delta \mathrm{T}} \varepsilon(A)\right]^{2}+\left[\frac{-Q}{A \Delta \mathrm{T}^{2}} \varepsilon(\Delta \mathrm{T})\right]^{2}}$

\section{Results}

Dielectric strength was measured for transformer oil$\mathrm{Al}_{2} \mathrm{O}_{3}$ nanofluid at various mois ture content present in the nanofluid, which was prepared at various sonication timings i.e., $1 \mathrm{hr}, 2 \mathrm{hr}$, and $3 \mathrm{hr}$. It is depicted in Figure 6. The performance of transformer oil nanofluid was decreased with the moisture content present in it. For all the sonication timings, the trend of decreasing breakdown voltage was similar and up to $100 \mathrm{ppm}$ of water present in the transformer oil, the decrement of breakdown voltage was rapid and then it was decreased at a slow pace. The breakdown voltage of transformer oil- $\mathrm{Al}_{2} \mathrm{O}_{3}$ nanofluid where moisture was kept under 10 ppm, was measured in the oil tester for various particle loadings of $\mathrm{Al}_{2} \mathrm{O}_{3}$ nanoparticles from 0.02 to $0.16 \%$ and is shown in Figure 7. It was observed that the breakdown voltage of prepared transformer oil $-\mathrm{Al}_{2} \mathrm{O}_{3}$ nanofluid was increased till the volume fraction of $0.1 \%$ and then reduced.

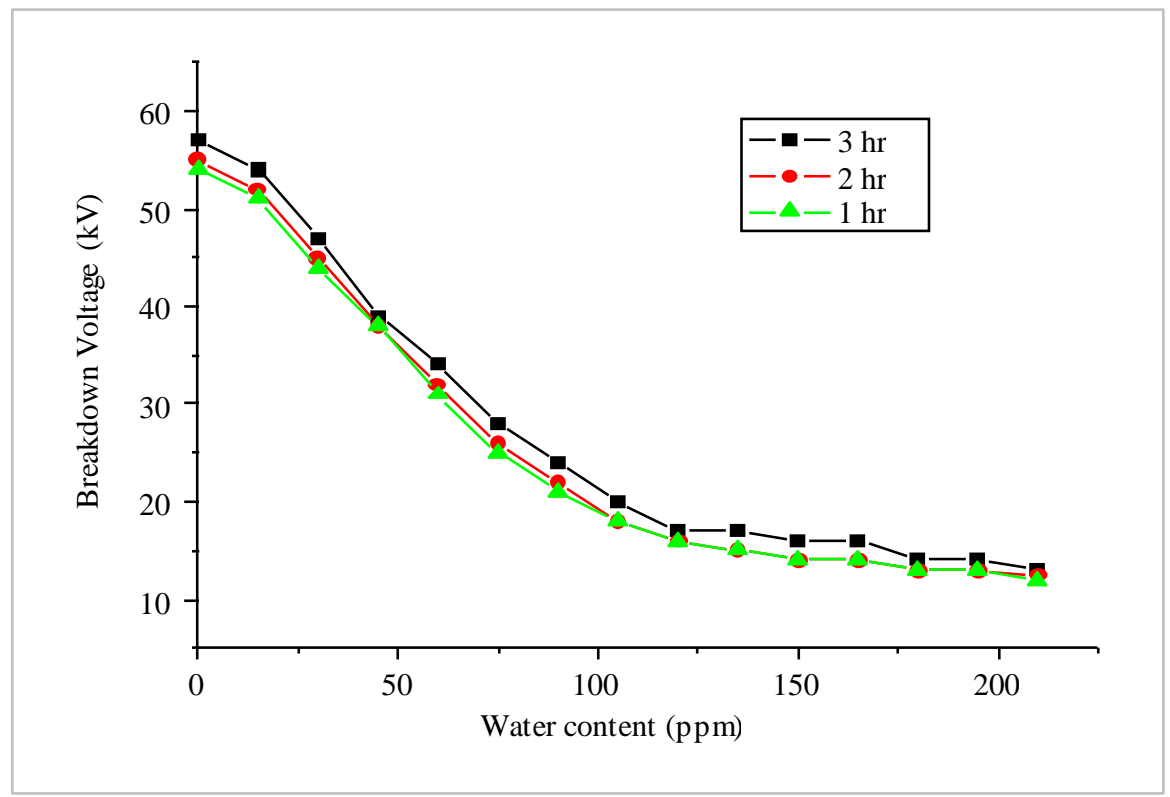

Figure 6 Breakdown voltage vs. water content for various sonication times

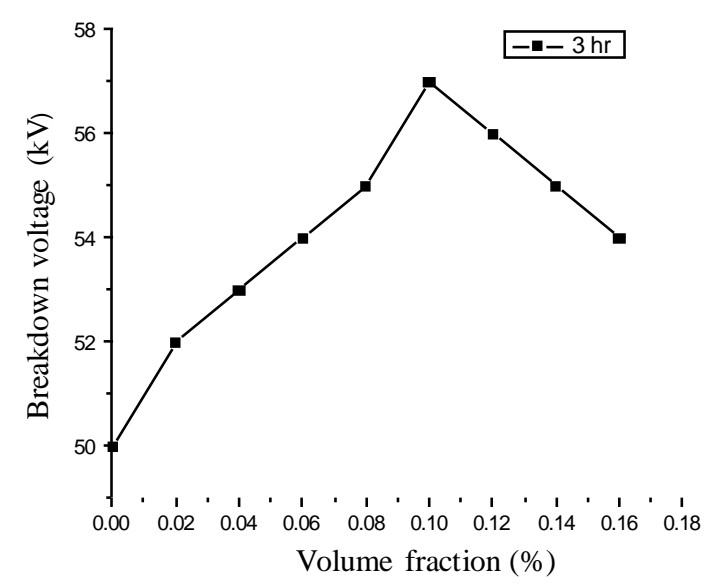

Figure 7 Breakdown voltage vs. volume fraction of nanofluid at $<10 \mathrm{ppm}$ moisture level 
Natural convection heat transfer experiments were conducted to determine the performance of transformer oil- $\mathrm{Al}_{2} \mathrm{O}_{3}$ nanofluid at various nanoparticle concentrations and for different heat fluxes. Temperatures on the surface of the vertical cylinder at the prescribed locations of thermocouples were recorded for various heat fluxes where transformer oil- $\mathrm{Al}_{2} \mathrm{O}_{3}$ nanofluid as a medium at $0.1 \%$ volume fraction is shown in Figure 8. Also, temperature readings were noted at the same height in the liquid. It was understood that along the axial direction, temperature of the cylinder was increased frombottom to top portion and this trend was similar for all the heat fluxes. It is due to the growth of boundary layer thickness from the bottom to the top. As a result, more heat transfer occurs at the bottom, and comparatively less heat transfer occurs at the top portion of the cylinder. And there was a fall in temperature at the top due to more exposure to the liquid.

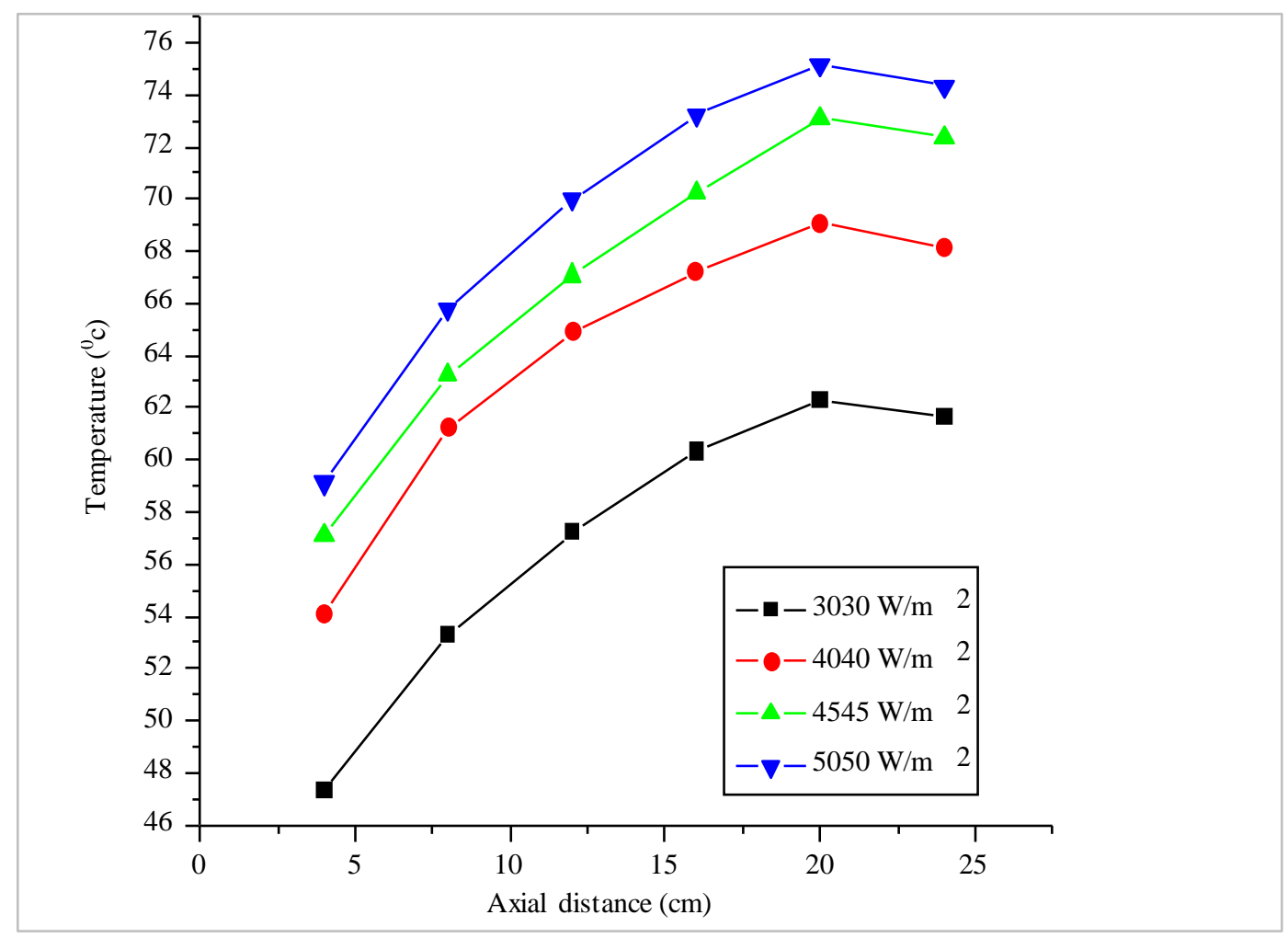

Figure 8 Temperature on the cylinder with axial distance for various heat fluxes

The average heat transfer coefficient was measured for various volume fractions of alumina nanoparticles in transformer oil -based $\mathrm{Al}_{2} \mathrm{O}_{3}$ nanofluid. The variation of the average heat transfer coefficient is shown in Figure 9. It is identified that, up to 0.1 vol\% concentration average heat transfer coefficient is increased and then it is decreased with furtherincrease of nanofluid volume concentration. At a heat input of $50 \mathrm{~W}$, the average heat transfer coefficient was 127 $\mathrm{W} / \mathrm{m}^{2} \mathrm{~K}$ at base fluid and it was increased up to 138 $\mathrm{W} / \mathrm{m}^{2} \mathrm{~K}$ at 0.1 vol\% particle loading was augmented by $8.7 \%$.
Thermal conductivity is the most important property of the nanofluid as it influences the cooling efficiency. With the addition of nanoparticles, the thermal conductivity of the nanofluid is increased as the thermal conductivity of nanoparticles is much higher than the carrier fluid. Heat transfer is the mechanism that depends on the movement of the molecules of the fluid. So it depends on the viscosity of the nanofluid also. The too much addition of the nanoparticles in a carrier fluid makes the nanofluid more viscous and will impede the heat transfer rate. The enhancement in the thermal performance occurs because, at lower concentrations, the performance is more dependent on thermal conductivity, and at higher concentrations it 
will depend on the viscosity rather than thermal conductivity. This effect is the reason for decreasing the thermal performance of the nanofluid at higher concentrations.

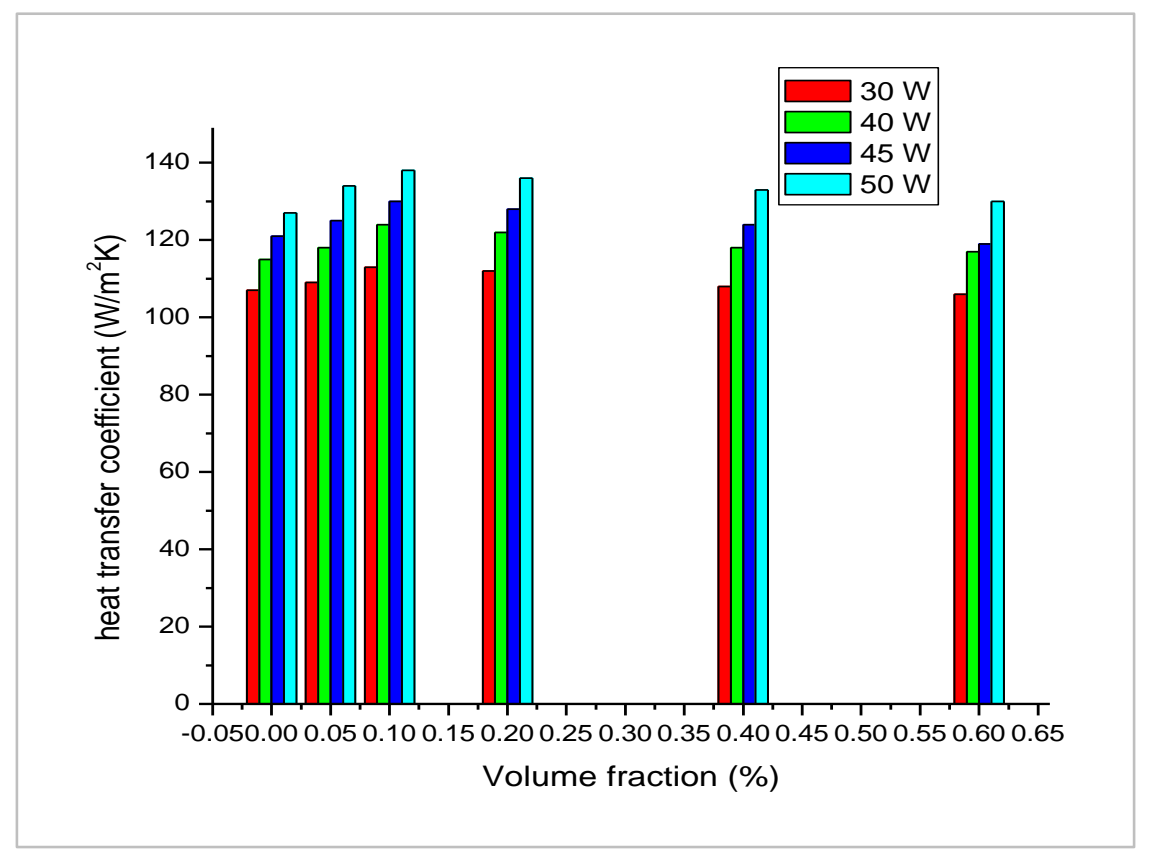

Figure 9 Change in heat transfer coefficient with volume fraction of different heat inputs

\section{Discussion}

A comparis on was done to study the effect of moisture content on heat transfer coefficient. The average heat transfer coefficient was determined for the various volume fractions of transformer oil $-\mathrm{Al}_{2} \mathrm{O}_{3}$ nanofluid when the nanofluid contains no moisture and with 10 ppm of moisture at 50W heat input and is shown in Figure 10. Nanofluid with the $10 \mathrm{ppm}$ of moisture content has a marginally higher heat transfer coefficient. With the addition of the moisture to nanofluid, the thermal conductivity of nanofluid will be increased because the thermal conductivity of water is more than the thermal conductivity of transformer oil $-\mathrm{Al}_{2} \mathrm{O}_{3}$ nanofluid [10]. So the addition of the moisture content of $10 \mathrm{ppm}$ led to a marginal increase in the heat transfer i.e., a maximum of $2.17 \%$ compared to transformer oil $-\mathrm{Al}_{2} \mathrm{O}_{3}$ nanofluid without moisture content. Comparison of percentage enhancement in heat transfer coefficient was done with Mansour and Elsaeed [21] and is presented in Figure 11. The maximum percentage enhancement in heat transfer coefficient was occurred at the same volume fraction of the nanofluid i.e., 0.1\%. Also observed from both studies, the volume fraction of nanofluid increases, the percentage enhancement was decreased. The difference in the enhancement was depended on the preparation of the stable nanofluid.

Thermal conductivity and viscosity are very much important thermophysical properties that influence the thermal performance of the nanofluid. Variations of thermal conductivity and viscosity of transformer oil$\mathrm{Al}_{2} \mathrm{O}_{3}$ nanofluid with temperature for different concentrations of nanoparticles are shown in Figure 12 and 13 respectively. It was identified that effective thermal conductivity (ratio of thermal conductivity of nanofluid to the thermal conductivity of base fluid) was increased with an increase in the \% volume fraction. As the thermal conductivity of nanoparticles was very much higher compared to the thermal conductivity of the base fluid, the effective thermal conductivity of the nanofluid was improved. The results of the effective thermal conductivity were compared with the classical theoretical models like Williams et al. [22], Maxwell [23] and experimental studies, like Das et al. [24], and observed that the results were very much within the acceptable range $( \pm$ $4.85 \%$ ). 
S. Ravi Babu et al.

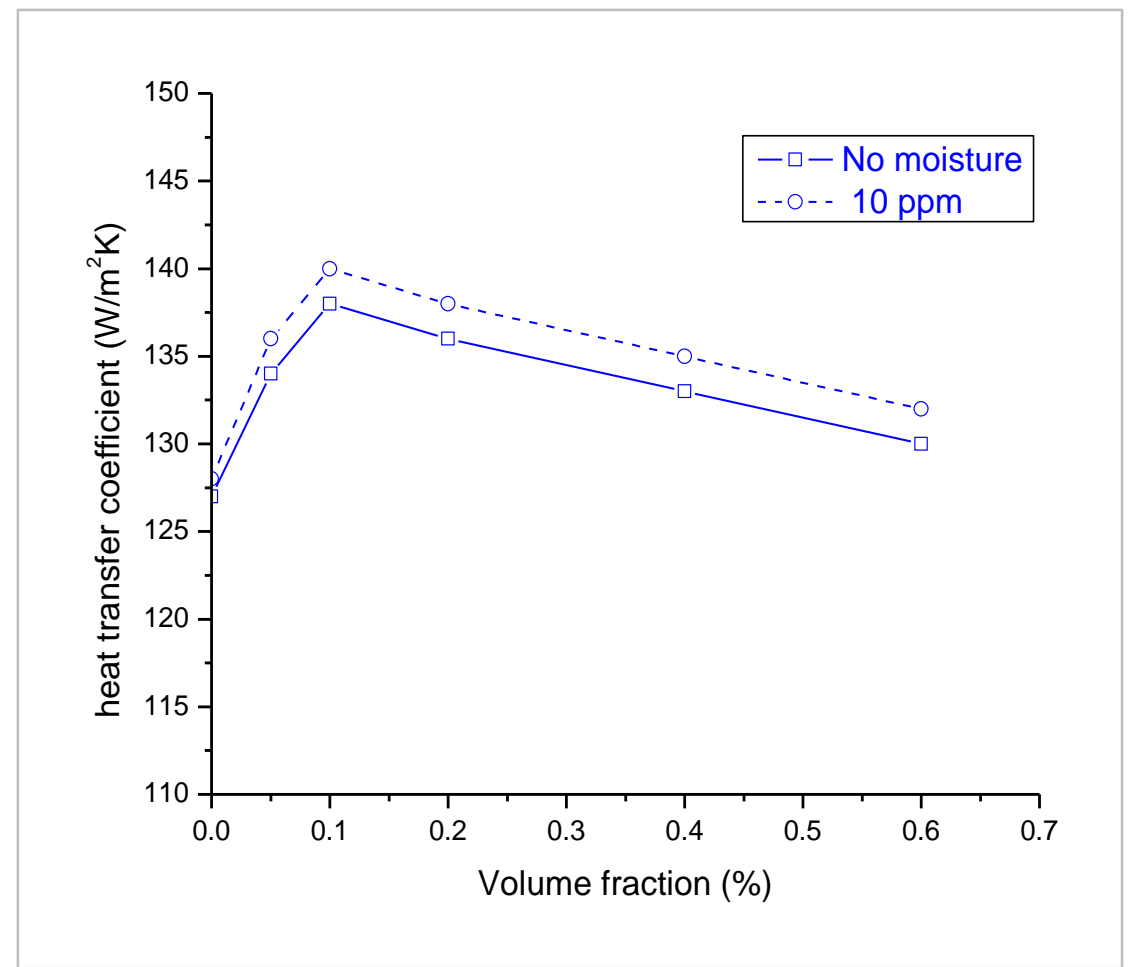

Figure 10 Heat transfer coefficient with volume fraction with and without moisture content at $50 \mathrm{~W}$

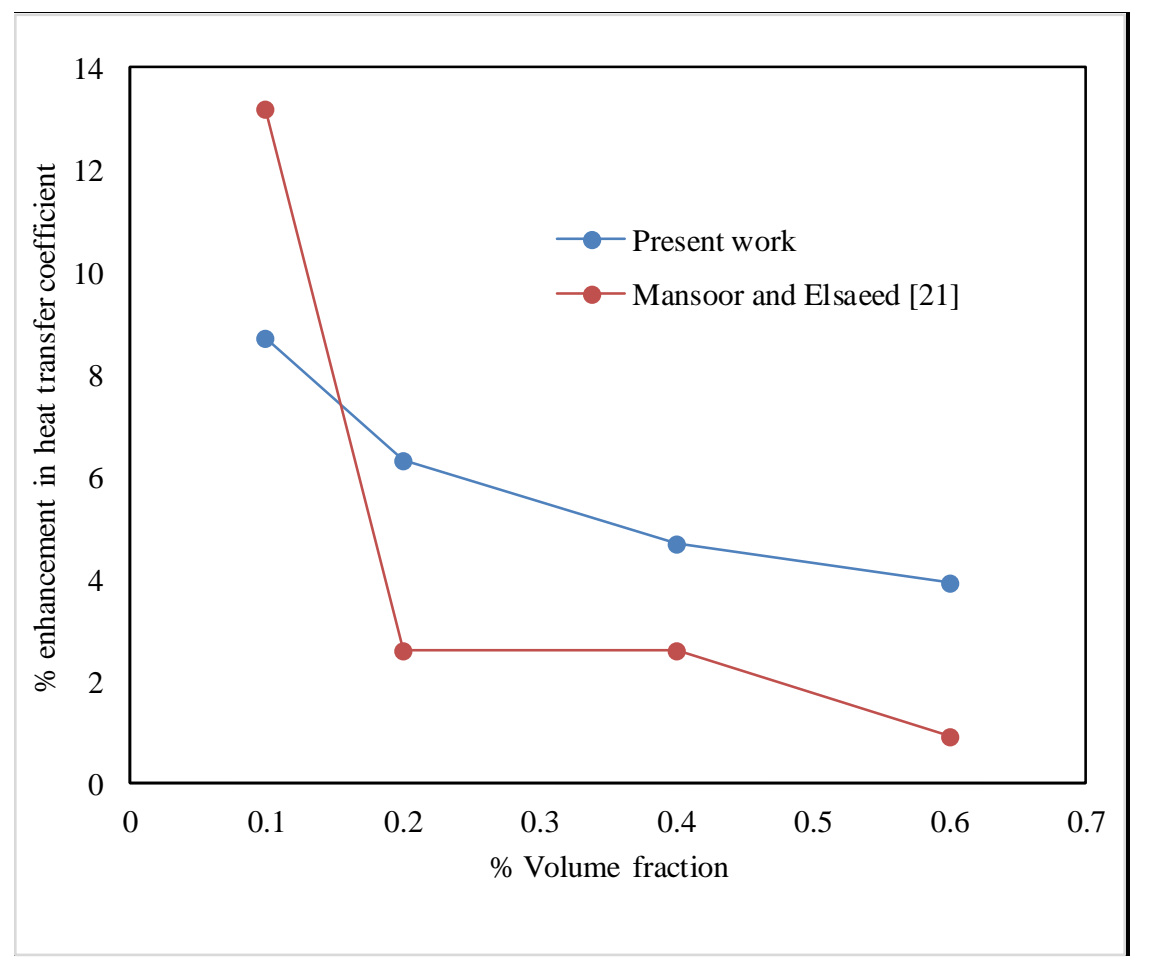

Figure 11 comparisons of percentage enhancement in heat transfer coefficient 


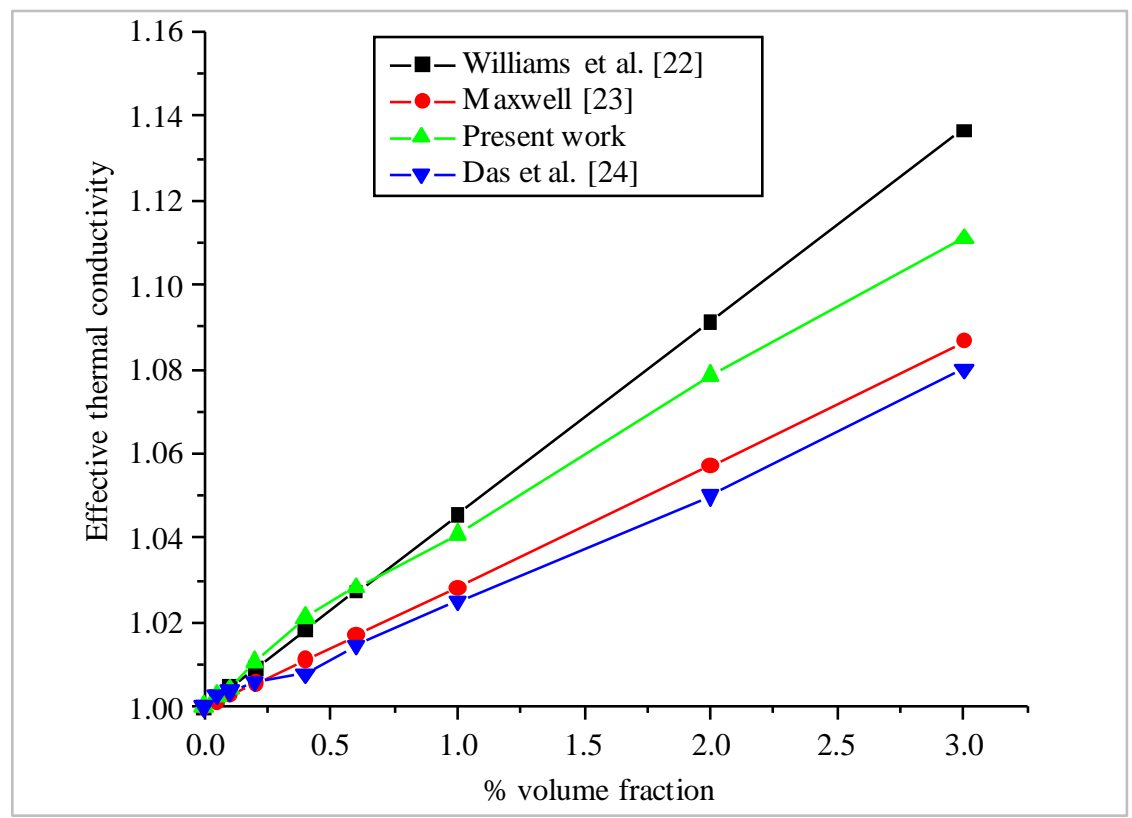

Figure 12 Effective thermal conductivity with volume fraction (\%)

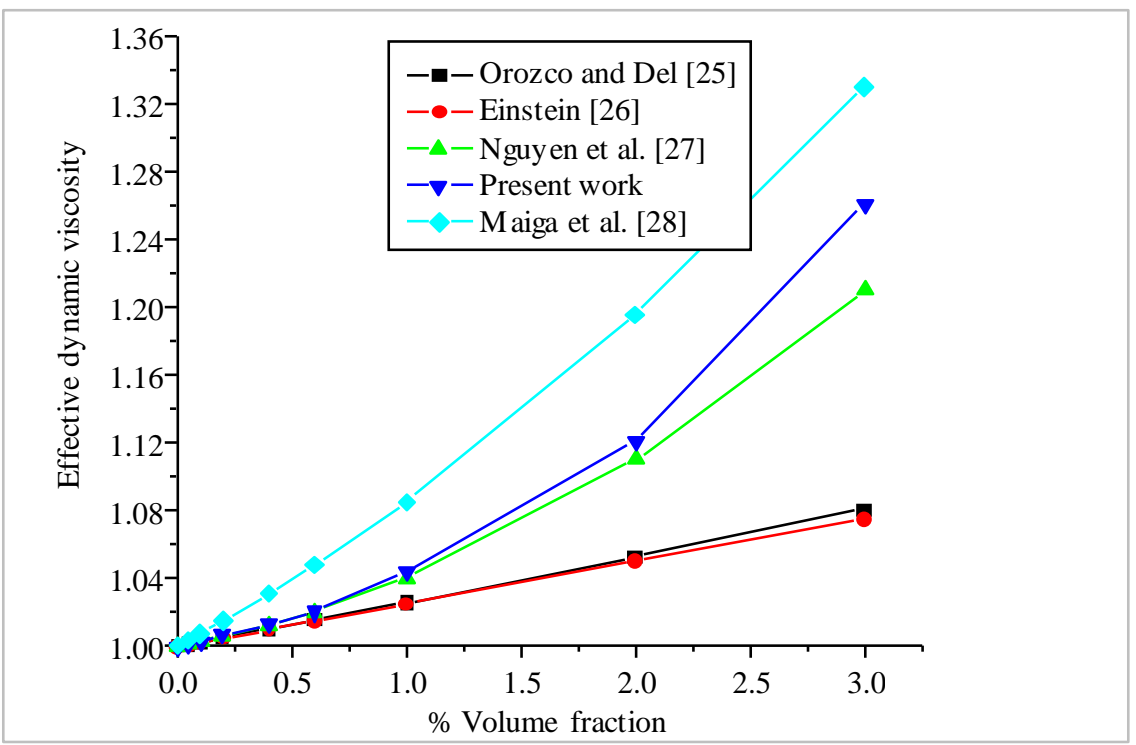

Figure 13 Effective dynamic viscosity with volume fraction (\%)

It was identified that effective dynamic viscosity (ratio of the viscosity of nanofluid to the viscosity of base fluid) was increased with an increase in the \% volume fraction. As the viscosity of nanoparticles was very much higher compared to the viscosity of the base fluid, the effective thermal conductivity of the nanofluid was improved. The results of the effective viscosity were compared with the classical theoretical models like Williams et al. [22], Einstein [26] and experimental studies, like Nguyen et al. [27] and
Maiga et al. [28] and observed that the results were very much within the acceptable range $( \pm 3.68 \%)$ and deviated much at higher volume concentrations compared to classical models. However, volume, fractions used in the present work were up to $0.6 \%$ only. Hence thermophysical properties are very much in the allowable range while comparing with the existing literature.

A complete list of abbreviations is shown in Appendix I 
6.1 Limitations of experimental study

The stability of the nanofluid, in the long run, is the main concern. The current study was not aimed at the effect of aging on the performance of the nanofluid. It can be further extended by doing the experiments for different time periods like 1 month, 2 months, and 3 months etc., for determining the aging effect on thermal performance of nanofluid.

\section{Conclusion and future work}

In this paper, the effect of moisture and sonication time on dielectric strength and heat transfer performance was investigated experimentally. Dielectric strength was measured for transformer oil- $\mathrm{Al}_{2} \mathrm{O}_{3}$ nanofluid at various moisture contents present in the nanofluid and different sonication timings like $1 \mathrm{hr}, 2 \mathrm{hr}$, and $3 \mathrm{hr}$ and observed that performance of transformer oil nanofluid was decreased with the moisture content present in it. At 3 hours of sonication, a marginal increase in breakdown voltage was observed. It was understood that the performance of transformer oil nanofluid was decreased with the moisture content present in it. It was also observed that the breakdown voltage of prepared transformer oil- $\mathrm{Al}_{2} \mathrm{O}_{3}$ nanofluid was increased till the volume fraction reaches $0.1 \%$ and then reduced. At a heat input of $50 \mathrm{~W}$, the average heat transfer coefficient was $127 \mathrm{~W} / \mathrm{m} 2 \mathrm{~K}$ at base fluid and it was increased up to $138 \mathrm{~W} / \mathrm{m} 2 \mathrm{~K}$ at $0.1 \mathrm{vol} \%$ particle loading was augmented by $8.7 \%$. The addition of the moisture content of $10 \mathrm{ppm}$ led to a marginal increase in the heat transfer with a maximum of $2.17 \%$ compared to transformer oil $-\mathrm{Al}_{2} \mathrm{O}_{3}$ nanofluid without moisture content. So it was observed that breakdown voltage and heat transfer coefficient are maximum at $0.1 \%$ volume fraction of nanofluid. This work can be extended to determine the effect of moisture for various nanofluids and compared.

\section{Acknowledgment}

The authors are very much thankful to the management of GMR Institute of Technology, Rajam for providing sufficient infrastructural facilities for completing this experimental study.

\section{Conflicts of interest}

The authors have no conflicts of interest to declare.

\section{References}

[1] Fernández I, Valiente R, Ortiz F, Renedo CJ, Ortiz A. Effect of $\mathrm{TiO}_{2}$ and $\mathrm{ZnO}$ nanoparticles on the performance of dielectric nanofluids based on vegetable esters during their aging. Nanomaterials. 2020; 10(4):1-18.

[2] Farade RA, Wahab NI, Mansour DE, Azis NB, Jasni $\mathrm{JB}$, Veerasamy $\mathrm{V}$, et al. Investigation of the effect of sonication time on dispersion stability, dielectric properties, and heat transfer of graphene based green nanofluids. IEEE Access. 2021; 9:50607-23.

[3] Xu F, Wang H, Xing S, Tang M, Zhang H, Wang Y. Seeking optimized transformer oil-based nanofluids by investigation of the modification mechanism of nanodielectrics. Journal of Materials Chemistry C. 2020; 8(22):7336-43.

[4] Rafiq M, Shafique M, Anam A, Ateeq M. Transformer oil-based nanofluid: the application of nanomaterials on thermal, electrical and physicochemical properties of liquid insulation-a review. Ain Shams Engineering Journal. 2021; 12(1):555-76.

[5] Bhatt M, Bhatt P. A review on electrical characteristics of nanofluid based transformer oil. Indian Journal of Science and Technology. 2019; 12(27):1-20.

[6] Suhaimi SN, Rahman AR, Din MF, Hassan MZ, Ishak MT, Jusoh MT. A review on oil-based nanofluid as next-generation insulation for transformer application. Journal of Nanomaterials. 2020.

[7] Lv YZ, Li C, Sun Q, Huang M, Li CR, Qi B. Effect of dispersion method on stability and dielectric strength of transformer oil-based $\mathrm{TiO}_{2}$ nanofluids. Nanoscale Research Letters. 2016; 11(1):1-6.

[8] Ghani SA, Muhamad NA, Chairul IS, Jamri N. A study of moisture effects on the breakdown voltage and spectral characteristics of mineral and palm oil-based insulation oils. ARPN Journal of Engineering and Applied Sciences. 2016; 11(8):5012-20.

[9] Kiran MR, Babu SR. Experimental investigation on natural convection heat transfer enhancement using transformer oil-TiO2 nanofluid. International Research Journal of Engineering and Technology. 2018; 5(7):1412-8.

[10] Ravi BS, Sambasiva RG. Buoyancy-induced natural convective heat transfer along a vertical cylinder using water- $-\mathrm{Al}_{2} \mathrm{O}_{3}$ nanofluids. Journal of Thermal Science and Engineering Applications. 2018; 10(3):1-7.

[11] Ashiquzzaman M, Mitra S, Molla NM, Chakma T, Nasrin KF. Testing of dielectric strength of transformer oil, insulation paper and corona effect of wire. In region 10 symposium 2020 (pp. 1026-9). IEEE.

[12] Danikas M, Sarathi R, Morsalin S. A short review of some of the factors affecting the breakdown strength of insulating oil for power transformers. Engineering, Technology \& Applied Science Research. 2020; 10(3):5742-7.

[13] Ghoneim SS, Sabiha NA, Hessien MM, Alahmadi A. Evaluation of dielectric breakdown strength of transformer oil with $\mathrm{BaTiO}_{3}$ and $\mathrm{NiFe}_{2} \mathrm{O}_{4}$ nanoparticles. Electrical Engineering. 2019; 101(2):369-77.

[14] Sumathi S, Rajesh R, Subburaj P. Investigation of dielectric strength of transformer oil based on hybrid $\mathrm{TiO}_{2} / \mathrm{Al} 2 \mathrm{O}_{3} / \mathrm{MoS}_{2}$ nanofluid using taguchi and response surface methodology. IETE Journal of Research. 2019:1-9.

[15] Kunju KB, Shemim SS. Dielectric properties of ecofriendly nanofluids. In journal of physics: conference series 2019 (pp. 1-6). IOP Publishing. 
[16] Abdi S, Harid N, Safiddine L, Boubakeur A, Haddad AM. The correlation of transformer oil electrical properties with water content using a regression approach. Energies. 2021; 14(8):1-14.

[17] Safiddine L, Zafour HZ, Rao UM, Fofana I. Regeneration of transformer insulating fluids using membrane separation technology. Energies. 2019; 12(3):1-13.

[18] Ali AR, Salam B. A review on nanofluid: preparation, stability, thermophysical properties, heat transfer characteristics and application. SN Applied Sciences. 2020; 2(10):1-17.

[19] Ji J, Lu W, Si C, Zhang S, Yao X, Wang W, et al. Overview on the preparation and heat transfer enhancement of nanofluids. In journal of physics: conference series 2020 (pp. 1-9). IOP Publishing.

[20] Zhou Y, Peng N, Wang Z, Cui W, Chen W, Sui S, et al. Modified propagating behavior of creeping streamers at $\mathrm{TiO} 2$ nanofluid/pressboard interface. Journal of Molecular Liquids. 2019.

[21] Mansoor DE, Elsaeed AM. Heat transfer properties of transformer oil-based nanofluids filled with $\mathrm{Al}_{2} \mathrm{O}_{3}$ nanoparticles. In international conference on power and energy 2014 (pp. 123-7). IEEE.

[22] Williams W, Buongiorno J, Hu LW. Experimental investigation of turbulent convective heat transfer and pressure loss of alumina/water and zirconia/water nanoparticle colloids (nanofluids) in horizontal tubes. Journal of Heat Transfer. 2008; 130(4).

[23] Maxwell JC. Electricity and magnetism. New York: Dover; 1954.

[24] Das SK, Choi SU, Patel HE. Heat transfer in nanofluids - $\mathrm{a}$ review. Heat Transfer Engineering. 2006; 27(10):3-19.

[25] Orozco D, Del CLF. Hydrodynamic behavior of suspension of polar particles. Encyclopedia Surface Colloid Science. 2005; 4:2375-96.

[26] Einstein A. Investigations on the theory of the brownian movement. Courier Corporation; 1956.

[27] Nguyen CT, Desgranges F, Galanis N, Roy G, Maré T, Boucher S, et al. Viscosity data for Al2O3-water nanofluid-hysteresis: is heat transfer enhancement using nanofluids reliable?. International Journal of Thermal Sciences. 2008; 47(2):103-11.

[28] Maiga SE, Palm SJ, Nguyen CT, Roy G, Galanis N. Heat transfer enhancement by using nanofluids in forced convection flows. International Journal of Heat and Fluid Flow. 2005; 26(4):530-46.

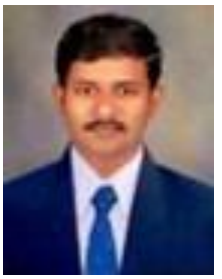

Dr. S. Ravi Babu, obtained his doctoral degree in 2020 in the area of heat transfer augmentation using nanofluids from Acharya Nagarjuna University, Guntur. He is working as Sr. Assistant professor in the department of Mechanical Engineering, GMRIT, Rajam. He published papers in various reputed international journals includes ASME. He was also awarded various teaching awards to his credit.

Email: ravibabu.s@gmrit.edu.in

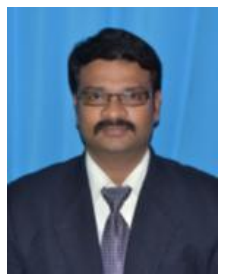

Dr. N.V.A. Ravi Kumar, obtained his doctoral degree in 2021 in the area of control sy stem engineering from JNTU$\mathrm{K}$, Kakinada. He is working as a $\mathrm{Sr}$. Assistant professor in the department of Electrical Engineering, GMRIT, Rajam. He published papers in various reputed international journals includes Electrical Engineering, Springer.

Email: ravikumar.nva@gmrit.edu.in

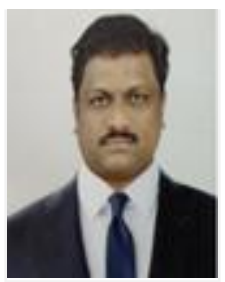

Dr. P. Ramesh Babu, Tadepalligudem, obtained his doctoral degree in 2015 in the area of thermal engineering from Andhra University, Visakhapatnam. He is working as a professor in the department of Mechanical Engineering, SASI Institute of Technology and Engineering, Tadepalligudem. $\mathrm{He}$ published papers in various reputed international journals and conferences.

Email: dr.prb@sasi.ac.in

\begin{tabular}{lll}
\begin{tabular}{l} 
Appendix I \\
\hline S. No
\end{tabular} & Abbre viation & Description \\
\hline 1 & ASTM & $\begin{array}{l}\text { American Society for } \\
\text { Testing Materials }\end{array}$ \\
\hline 2 & IEC & $\begin{array}{l}\text { Israel El } \\
\text { Corporation }\end{array}$ \\
\hline 3 & $\mathrm{Al}_{2} \mathrm{O}_{3}$ & Aluminum Oxide \\
\hline 4 & $\mathrm{TiO}_{2}$ & Titania \\
\hline 5 & $\mathrm{MoS}_{2}$ & Molybdenum Sulphide \\
\hline 6 & $\mathrm{Fe}_{2} \mathrm{O}_{3}$ & Ferric Oxide \\
\hline 7 & $\mathrm{SiO}_{2}$ & Silica \\
\hline 8 & $\mathrm{BN}^{2}$ & Boron Nitride \\
\hline 10 & $\mathrm{ZnO}$ & Zinc Oxide \\
\hline 11 & $\mathrm{ANOVA}$ & Analysis of Variance \\
\hline 12 & $\mathrm{~nm}$ & Nano Meter \\
\hline 13 & Cr-Al & Chrome-Aluminium \\
\hline 14 & ppm & Litre per minute \\
\hline & & Parts per million \\
\hline
\end{tabular}

